\title{
EL LENGUAJE DE LOS BALCONES
}

\author{
THE LANGUAGE OF BALCONIES
}

\section{Ricard MORANT MARCO Arantxa MARTÍN LÓPEZ}

\author{
Universitat de València \\ ricardo.morant@uv.es / arantxaml@ono.com
}

Resumen: El presente artículo analiza los usos comunicativos de los balcones, que, además de cumplir una función estética y ambiental, se han convertido, a lo largo del tiempo, en unos soportes de gran riqueza expresiva, especialmente en el paisaje urbano.

Abstract: In the present article, we analize the communicative uses of balconies. Besides their ambiental and esthetic function, balconies have become incredibly expressive supports over time, especially in cities.

Palabras clave: Balcones. Soportes comunicativos. Lenguaje visual.

Key Words: Balconies. Communicative supports. Visual language. 


\section{INTRODUCCIÓN}

El objetivo de este artículo es llevar a cabo una primera aproximación sobre un aspecto lingüístico no estudiado hasta el momento: el referente a los usos comunicativos de los balcones en la sociedad española actual.

$\mathrm{Al}$ revisar las investigaciones realizadas sobre los soportes comunicativos del paisaje callejero, se observa que mientras algunos de ellos, como los muros o el mobiliario urbano, han llamado la atención de los investigadores (Garí, 1995; López Jiménez, 1998; Jornet, 2008; Cano, García, Castilla y Cabrera, 2010), otros, como los balcones, permanecen aún por explorar, a pesar de su trascendencia ${ }^{1}$.

Precisamente, al papel de los balcones como soporte de difusión dedicamos las siguientes páginas. $\mathrm{Y}$ es que estos elementos arquitectónicos no sólo cumplen una función estética y ambiental sino que han acumulado una gran fuerza comunicativa, adaptando sus posibilidades de interlocución entre el dominio particular y el social, y se han convertido en la actualidad en escenarios perfectos para la expresión colectiva.

Para la realización del artículo nos hemos basado, aparte de en una amplia bibliografía multidisciplinar, en numerosos artículos de prensa y referencias de Internet, que nos han permitido investigar los balcones desde el punto de vista comunicativo, y hemos seguido dos pasos. En un primer momento, hemos recogido una muestra exhaustiva y representativa de balcones recorriendo las avenidas, plazas y calles de pueblos y ciudades. Y hemos explorado, además, el paisaje mediático escrito, audiovisual y virtual, donde aparecen cientos de fotos de todo tipo de balcones ${ }^{2}$ e informaciones que reflejan su protagonismo en la transmisión de muy diversos tipos de mensajes entre los miembros de una comunidad. En la segunda fase del trabajo hemos analizado, clasificado, descrito y explicado los soportes seleccionados con el propósito de llegar a una caracterización de los mismos. Esta tarea no ha resultado sencilla, pues exige observar con nuevos ojos un espacio cotidiano que suele pasar desapercibido y requiere una mirada especial y atenta que

\footnotetext{
${ }^{1}$ Resulta curioso, además, que al describir específicamente las diversas formas de publicidad exterior, autores como Rodríguez, Suárez y García (2008: 155), mencionen «las vallas, la publicidad móvil o semimóvil (anuncios en el interior o exterior de taxis o autobuses; anuncios en remolques), el mobiliario urbano (marquesinas, mupis, relojes, aseos o cabinas), los carteles y las banderolas» pero que no se mencionen los balcones.

${ }^{2}$ Basta colocar en el buscador de Google la expresión fotos de balcones para que aparezcan más de mil.
} 
capte hasta el más mínimo detalle de esta parte principal de muchas casas y edificios.

El trabajo se divide en dos apartados. En el primero, se recogen las definiciones que algunos diccionarios incluyen del término balcón, que no hacen referencia ni a su original utilidad ambiental ni a las múltiples capacidades comunicativas. Estas capacidades son precisamente las que, en la actualidad, aprovechan los diferentes tipos de emisores que se asoman a él desde los edificios a los que pertenecen - ya sean públicos, institucionales o particulares -, para difundir una amplia variedad de mensajes, unas veces, de modo voluntario y otras, involuntario. El segundo apartado se centra plenamente en el objeto de estudio del artículo, los usos actuales de los balcones mensajeros, como elementos esenciales de la sociedad del espectáculo en que vivimos. En él se analizan tanto las peculiares condiciones en que deben ser descifrados los mensajes explícitos que lanzan como las funciones principales que desempeñan y que derivan en una clasificación de los mismos como balcones informativos o referenciales, balcones conativos, balcones expresivos y balcones estéticos. El artículo, después de haber comentado brevemente los usos de los balcones en el pasado y de examinar sus usos en el presente, se cierra con unas conclusiones, que dejan abierto un interrogante final sobre su futuro como soportes comunicativos, ante los cambios que el creciente uso de las nuevas tecnologías ya están generando en los comportamientos sociales.

\section{LA VOZ MÚLTIPLE DE LOS BALCONES}

Las escuetas definiciones que ofrecen los diccionarios sobre los balcones no hacen honor a su trascendencia como espacios comunicativos que participan de la esfera pública, a pesar de estar sujetos claramente a un ámbito privado, por lo que podrían calificarse como espacios semipúblicos, semiprivados o público-privados.

El Diccionario de uso del español de María Moliner (1998: 329), en la primera de sus tres acepciones, define balcón como «Hueco abierto en el muro de un edificio que se diferencia de las ventanas en que empieza desde el suelo de la habitación y tiene en general un piso saliente con antepecho sobre el que se puede estar [...]». En sus siguientes definiciones recoge sus características y usos y los traslada a espacios más abiertos, llegando a considerar como balcón «Cualquier lugar con barandilla para asomarse».

Tampoco refleja su fuerza expresiva el Diccionario visual de términos arquitectónicos (VVAA, 2008: 102), que define así este término: «Hueco 
abierto al exterior, con suelo en voladizo, generalmente cerrado a media altura por una barandilla o pretil», si bien a continuación resalta otras características más allá de su aspecto físico: «Representa un elemento simbólico desde un punto de vista literario (Romeo y Julieta) e histórico (discursos de mandatarios, ceremoniales, revistas a tropas, etc.)».

Según Ricardo Sabaleta, especialista en preservación y restauración del patrimonio histórico (Maldonado, 2011), en principio, «los balcones tenían una vocación eminentemente ambiental», ya que su construcción abierta, traslúcida y el manejo de los balaustres de las barandas dejaban que el viento los cruzara y circulara a través de toda la casa, lo que permitía que hubiera un «ambiente fresco y confortable». Esta utilidad del balcón como climatizador, sin embargo, parece que se está perdiendo pues nos encontramos, como sostiene Agüiero:

En tiempos donde el confort al interior de las casas en viviendas, oficinas y demás espacios arquitectónicos se realizan a través de medios mecánicos, con los perjuicios tantos sociales, económicos, así como del medio ambiente (2009: 6).

Y ocurre, además, que esta disminución de la función ambiental de los balcones se está produciendo de modo paralelo al enriquecimiento de la función comunicativa que siempre han desempeñado. Y así, si tradicionalmente han permitido la comunicación entre vecinos como auténticas travesías en el aire y espacio para la interlocución discreta - menos público que la calle, pero menos privado que el hogar-, en la actualidad el diálogo que propician es más social que personal y alcanza un eco mucho mayor.

Esta faceta comunicativa no es exclusiva de un tipo específico de balcón, sino que está presente tanto en los balcones públicos oficiales, como en los institucionales-colectivos y en los particulares. Todos ellos tienen en común que lanzan algún tipo de información al transeúnte sobre lo que alberga su interior. Los oficiales se caracterizan porque no dicen mucho de cómo son, sino lo que son sus ocupantes. De hecho, suele reconocerse un edificio oficial (ayuntamiento, consejería, consulado, etc.) por la presencia de determinados elementos en sus fachadas y balcones, como las banderas ${ }^{3}$.

\footnotetext{
${ }^{3}$ Según indica José Antonio de Urbina (1989: 250), en nuestro país, el uso de la bandera nacional está regulado por la Ley 39/81, de 28 de octubre (artículos 6 y 7). Tanto en los balcones como en otros sitios oficiales donde se coloque, debe ocupar «siempre lugar destacado, visible y de honor». Se entiende como tal, cuando el número de banderas que ondeen juntas sea impar, la posición central y, si es par, «de las dos posiciones que ocupan el centro, el de la derecha de la presidencia si la hubiera o la izquierda del observador». En relación con las banderas, encontramos casos curiosos, como el de la
} 
Además de los balcones de edificios gubernamentales, hay otros balcones públicos, como los institucionales o vinculados a partidos políticos, asociaciones o cualquier entidad de carácter colectivo, que muestran sus mensajes a los viandantes. Las sedes de partidos políticos, por ejemplo, aprovechan sus balcones para exhibir sus logos identificativos, para lanzar sus eslóganes de campaña y, llegado el caso, para celebrar una victoria. Así lo hizo el Partido Popular, cuando convirtió el balcón de su sede en la calle Génova de Madrid - que hasta ese momento había lucido el mensaje de campaña: Súmate al cambio - en el balcón de la victoria, tras conocer los resultados de las elecciones generales del 20 de noviembre de 2011. La nueva pancarta decía: Gracias.

Otros muchos balcones reflejan la identidad de sus propietarios, indicando quiénes son y dónde están - y, a veces, algún mensaje más - , como los de hoteles, academias, negocios, asociaciones y colegios profesionales que tratan así de llamar la atención de quienes transitan por la calle. Por ejemplo, en nuestro país, ante la gripe A, diversos colegios de médicos colgaron de sus balcones una pancarta que aconsejaba evitar el contacto físico, con el texto: No beses, no des la mano: di hola.

Finalmente, los balcones particulares constituyen un espacio para la expresión de quienes los habitan. Éstos lanzan mensajes muy distintos, desde los de carácter político (;El 15-M somos todos! iSonríe y despierta!) hasta los de tipo social (Queremos custodia compartida ya), pasando por los de índole comercial (Particular alquila habitaciones a estudiantes) o amoroso, como el siguiente, exhibido en el balcón de una calle céntrica de Madrid: «Hoy no te traigo oro porque no tiene lugar en el cielo, no te traigo flores porque se marchitan y caen al suelo... Te traigo este verso más simple pero que está hecho con todo mi $\mathbb{C}$. Te quiero. Alfonso» ${ }^{4}$.

Desde la perspectiva comunicativa, los balcones difunden mensajes implícitos sobre quien vive en el interior, que se transmiten de modo involun-

Casa Consistorial de Alfàs del Pi (Alicante), que exhibe en su balcón, además de la bandera de España, de la Comunidad Valenciana y de la Comunidad Europea, la de Noruega en determinadas fechas, puesto que un porcentaje muy elevado de residentes procede de este país nórdico. Así, todos los años, el 17 de mayo, día nacional noruego, se iza esta bandera en el balcón municipal. El 25 de julio de 2011 este ayuntamiento lució también la bandera de Noruega aunque a media asta, en señal de duelo por las víctimas de los atentados ocurridos el 22 del mismo mes en dicho país.

${ }^{4}$ Como se señala en http://blogs.km77.com/nimeva/7563/te-quiero-desde-mi-balcon, «Alfonso podría haber escrito un sms a su pareja diciéndole que le quería, o, para airearlo a los cuatro vientos, podía haberlo publicado en su muro de Facebook, suponiendo que lo utilizase, pero no me digáis que no es bonito, y más apasionado, que lo haya escrito con letras grandes y colgado de su balcón». 
tario. A ellos se refiere Miguel Mesa (2011) cuando afirma que, a través de los balcones, «accedemos parcialmente y sin compromiso, a la vida de los otros». Y es que, a partir de su apariencia, se puede llegar a deducir la edad, el sexo, la clase social, la ideología, los gustos y hasta el carácter de sus dueños ${ }^{5}$.

Pero, además, los balcones pueden actuar como pantallas o altavoces y transmitir voluntariamente mensajes explícitos, tanto de carácter verbal (una palabra o una frase) como no verbal (una bandera o un lazo), convirtiéndose en balcones mensajeros, a la vista de los peatones, conductores y pasajeros de vehículos públicos y privados que transitan por calles y avenidas. Éstos son precisamente los que constituyen nuestro objeto de estudio y a ellos nos referimos en el siguiente apartado, pues son muy habituales en la sociedad actual.

\section{LOS USOS ACTUALES DE LOS BALCONES MENSAJEROS}

Hoy, los balcones han enriquecido su faceta comunicativa incorporando nuevos usos que reflejan las características de una sociedad del espectáculo ${ }^{6}$,

\footnotetext{
${ }^{5}$ Por ejemplo, si hay niños en la casa, en el balcón se suelen incorporar vallas de protección y, a veces, albergar juguetes, molinillos y globos. El sexo es otra de las características que se puede conocer a través del balcón cuando en él hay ropa tendida o se muestran algunos mensajes. El nivel adquisitivo se refleja a través del material de construcción y la decoración. Y la ideología, afinidades políticas, deportivas y religiosas, a través de elementos como pancartas y banderas. También los gustos y preferencias del propietario se transmiten al exterior, puesto que determinan su uso principal. Así, el balcón se utiliza muchas veces como mirador, y otras, se convierte en estancia, sobre todo cuando llega el buen tiempo; jardín o huerto urbano; hábitat de animales domésticos; almacén de alimentos y bebidas; tendedero; espacio para ventilar ropa y zapatos; garaje de pequeños vehículos; observatorio astronómico; estación meteorológica; locutorio; refugio para fumar; trastero, donde se deposita lo que estorba en el interior y hasta antenas parabólicas o aparatos de aire acondicionado; o lugar desde el que lanzar desperdicios. Aparte de indicar las preferencias de su dueño -a través de su uso principal- los balcones envían otros mensajes matizando su carácter: si tiene plantas muertas, es despreocupado; si lo ha cerrado, necesita tener más espacio privado; si hay rejas, es precavido o temeroso, considera que su casa es vulnerable y probablemente ha tenido una visita de los ladrones; si tiene las persianas bajadas, desea preservar su intimidad; si coloca las persianas por encima de la barandilla o baja el toldo, se previene del calor...

${ }^{6}$ A esta sociedad se refiere Vicente Verdú (2003: 11) explicando que en ella «la representación ha ganado la batalla y lo real se convalida por la realidad del espectáculo» y que para que se haya producido este cambio, ha sido necesario: «primero, convertir al ciudadano en espectador y, segundo, vender las entradas a todo un planeta homogeneizado». El filósofo alemán Boris Groys afirmaba, al respecto, en una entrevista realizada por José Andrés Rojo (2008): «Estamos en la cultura del espectáculo. Lo que está cambiando es que ahora todo el mundo quiere ser protagonista, todos quieren mostrar lo que saben hacer, y de paso tener éxito [...] todos esos afanes de proyectarse, de crear espectáculo, se sostienen en una hipótesis imaginaria: que hay alguien ahí».
} 
en la que la comunicación - sobre todo, la audiovisual -, resulta esencial. Estos nuevos usos, a pesar de su carácter novedoso, mantienen vínculos con los que han tenido en el pasado, y, así, de su papel ancestral han heredado, por un lado, su condición de espejo doble - tanto de quien vive en el interior como de la sociedad misma - y, por otro lado, la valoración de su notoriedad en el marco de la calle, que en ambos casos se considera como un gran escenario público. De hecho, los balcones siguen participando en las principales celebraciones de la comunidad de la que forman parte y, de este modo, en la transmisión de la alegría de la fiesta y el establecimiento de lazos comunitarios, pero han desarrollado considerablemente sus capacidades comunicativas ${ }^{7}$.

Los balcones son en la actualidad un excelente soporte para la difusión de mensajes muy diversos - a través de los que se expresan tendencias políticas, deportivas, religiosas y culturales - y espacios muy codiciados para los anuncios publicitarios, debido a su visibilidad - en el exterior-, que les garantiza un gran impacto. Su trascendencia como soportes comunicativos radica precisamente en su presencia permanente - ante los ojos de todo el mundo, durante 24 horas al día -, si bien tienen como contrapartida que se dirigen a un público habitualmente apresurado. Esta circunstancia, determina, en gran medida, la forma de los mensajes expuestos y, en este sentido, las palabras de Breva y Balado (2009: 3), referidas a la publicidad exterior, son muy claras:

Cuando vemos un anuncio de exterior, por la calle, no solemos parar a leer el texto, sino que hemos de verlo mientras andamos o conducimos, consecuentemente contamos con muy poco tiempo de lectura y atención.

Por eso, añaden estas autoras (2009: 14) que «La notoriedad y la relevancia del mensaje creativo, las posibilidades de cada ubicación deben ser medidas con lupa». Y, así, quienes quieren lanzar sus mensajes a través de un balcón deben valorar su grado real de visibilidad - del que depende la facilidad de su descodificación y la interpretación final - , que viene determinada por la ubicación, entendida en un sentido amplio, teniendo en cuenta

\footnotetext{
${ }^{7}$ Carmen Ortiz (2006: 205) explica la actualización de la fiesta tradicional y su puesta en escena, como modelo de nuevas celebraciones, refiriéndose concretamente a las deportivas: «La fiesta -un hecho cultural de primer orden en nuestro país- es el referente empleado por los medios de comunicación, por los políticos y los directivos de los clubes, pero también por los hinchas, para la categorización de su participación masiva, y muchos elementos de las fiestas populares [...] aparecen en el primer plano de la práctica de las celebraciones».
} 
cuestiones como la distancia entre mensaje y receptor, la altura ${ }^{8}$, la colocación dentro del balcón ${ }^{9}$, la calle, el tipo de edificio o la existencia de semáforos que en los momentos de espera permitan detenerse ante él. De hecho, no tiene la misma incidencia el texto ;En Sanidad, los recortes matan! si se exhibe en el balcón de un hospital que en el de una casa particular; ni tampoco si se cuelga en una calle transitada por peatones y conductores, que en una calle periférica y tranquila donde casi nunca pasa nadie. Y así lo resaltan Rodríguez, Suárez y García (2008: 158), refiriéndose también a la publicidad exterior, cuando afirman:

Puesto que un elemento clave en el éxito de este tipo de publicidad es el lugar concreto en que se sitúe, existe una fuerte competencia entre los anunciantes por conseguir unas buenas ubicaciones para sus mensajes.

Y es que, en nuestra sociedad del espectáculo, no basta con considerar la ubicación, ya que los mensajes de los balcones rivalizan entre sí por destacarse y sitúan al hipotético lector en un paisaje saturado de información, contaminado visualmente (Castañeda, 2009: 25). Por esta razón, podríamos decir, acogiéndonos a las palabras del publicista Luis Bassat, que si se pretende ser eficaz, los mensajes exteriores han de ser como un «puñetazo en el ojo» porque «La batalla de la calle se debe ganar por K.O.» (1993: 219). Explica Bassat que es preciso asegurar la concisión y la brevedad, ya que «Es un mensaje visto y no visto, que se cuela por nuestros ojos casi de manera involuntaria», por lo que «debe ir al grano y asegurarse de poder ser comprendido en... ; tres segundos!» (1993: 222-223). En el mismo sentido, García-Uceda (2008: 342) afirma: «el mensaje deber ser sencillo y comprensible. Debemos reducirlo a su mínima expresión en argumentos y ampliarlo a su máxima expresión visual y gráfica ${ }^{10}$.

Porque, además de la concisión, ante el reto de atrapar la mirada de los transeúntes, quien compone el mensaje que se coloca en el balcón cuenta con las numerosas posibilidades que le ofrece el lenguaje visual (Acaso, 2009; Costa, 2003) para hacerse notar, utilizando diferentes códigos, como el ti-

\footnotetext{
${ }^{8}$ Los balcones más cercanos al suelo son los más visibles. En cambio, los más altos deben valerse de otros recursos (efectos luminosos, nuevas tecnologías...) para atraer la atención.

${ }^{9}$ No tiene la misma notoriedad un mensaje colocado en la barandilla, en el toldo o en la parte superior de la puerta del balcón, por ejemplo.

${ }^{10}$ No resulta difícil probar que tiene más posibilidades de ser leído el mensaje de un balcón con un cartel conciso, del tipo Se alquila, junto a un número de teléfono, que otro que incluya toda esta información: Edificio C41. Live \& Work. Apartments and Lofts for Rent. Rediscover urban living in Valencia. For further information please contact Tel:.... E.mail: nag@....
} 
pográfico, el cromático y el gráfico. No impacta igual un cartel de Disponible en letras mayúsculas que en minúsculas; ni uno escrito a mano que uno realizado en ordenador; no tiene el mismo efecto un letrero con la leyenda $S e$ alquilan trasteros en amarillo claro, que en rojo; ni resulta tan sorprendente un texto con el rótulo Clínica dental, que otro con las mismas palabras pero acompañado de un dibujo gigante de una muela. Y es que, como explica Gubern (1988: 352-353), ante la abundancia de información, el destinatario dirige su mirada hacia los mensajes que más suscitan su empatía:

Ante tal avalancha de estímulos, los órganos de recepción de cada ciudadano operan selectivamente y en esta operación discriminatoria seleccionan: (a) los de mayor agresividad psicológica (es decir, aquellos que por su originalidad e imprevisibilidad consiguen abrirse paso entre una masa de estimulos banales), y (b) aquellos que coinciden con los intereses o refuerzan las convicciones del receptor.

Así pues, en nuestra sociedad los balcones intentan abrirse paso y hacer resaltar sus mensajes, construidos a partir de elementos verbales, no verbales o de una combinación de ambos ${ }^{11}$, que, unas veces, son permanentes -cuando, por ejemplo, indican qué hay en el interior (Residencia Universitaria Femenina Ntra. Sra. del Gave) y otras, efímeros -cuando dejan oír su voz en determinadas fechas (a través de la bandera del arco iris el Día del orgullo gay) o ante acontecimientos concretos (Oktoberfest. Plaza de toros. Valencia. $4^{a}$ Edición 19 abril al domingo 6 de mayo $)^{12}-$, y que también pueden ser estáticos o dinámicos - cuando, por ejemplo, indican intermitentemente los horarios con rótulos luminosos - . Sean del tipo que sean, parece claro que estos particulares elementos de las fachadas reflejan lo que sucede en nuestro entorno, haciéndose eco de los problemas e inquietudes de una comunidad, como pueden ser la contaminación acústica (Queremos dormir), la crisis inmobiliaria (STOP desahucios) o la situación política y económica (Indignate).

Teniendo en cuenta la finalidad primordial de sus mensajes, los balcones pueden ser informativos o referenciales, conativos, expresivos o estéticos,

${ }^{11}$ En los mensajes de los balcones actuales -frente a los tradicionales en los que predominan los elementos no verbales-, han ido ganando protagonismo los elementos verbales. Y, así, aunque sigue utilizándose un lenguaje no verbal -a través de sábanas, banderas, luces, lazos...- es cada vez mayor el empleo del lenguaje verbal, que se despliega sobre carteles y pancartas.

${ }^{12}$ Entre unos y otros, resultan curiosos los balcones que exhiben mensajes anacrónicos, como este del Colegio Público Santa Teresa: Santa Teresa. Col.legi Públic de Pre-escolar i Educació General Bàsica. Generalitat Valenciana. 
aunque, como veremos, a menudo pueden confluir simultáneamente varias funciones en un mismo balcón ${ }^{13}$.

Los balcones informativos o referenciales ofrecen información a través de mensajes abiertos, dirigidos a todos cuantos los ven. En este grupo se encuentran los balcones señalizadores que son los que exhiben, por ejemplo, las academias, pensiones y diferentes tipos de establecimientos y negocios - resaltando su presencia y su misión (Depilación Láser. Clínica Varices Sin Cirugía) -; o los que muestran carteles de rehabilitación, alquiler o venta de un inmueble (Edificio en venta. 2 locales comerciales en rentabilidad y $13 \mathrm{vi}$ viendas. B Sabadell / Solvia. Comercializa CBRE. C B Richard Ellis 96316 $2890)^{14}$. Para lanzar sus mensajes, algunos balcones sólo emplean palabras (hôme youth hostel) y otros las refuerzan con la ayuda de un símbolo. A estos últimos se refiere Laguna (2010), al indicar cómo hacer visualmente atractivo un establecimiento:

Si el comercio es específico, como una farmacia o una óptica, al rótulo de letras corpóreas, se le añadirá un elemento característico que indique la presencia del negocio, como la típica cruz, en el caso de las boticas, o el símbolo de unas gafas, en el caso de los centros de visión.

Carmen Galán (2011: 18) explica las ventajas de esta «forma icónica de leer», que no es algo reciente ${ }^{15}$ :

[...] permite una lectura rápida y simultánea en algunos casos en los que la escritura alfabética supondría un problema (por ejemplo en los carteles de información de las autopistas); de hecho, en las épocas de analfabetismo constituyeron el medio didáctico más idóneo, medio que todavía está presente tanto en las cartillas de iniciación a la lectura alfabética como en la barra de herramientas de un ordenador (la papelera, el sobre para indicar correo, el

13 Por ejemplo, los balcones festivos son predominantemente expresivos, por la carga de sentimientos que transportan, pero pueden ser también estéticos - por el embellecimiento que producen- e informativos - puesto que indican la existencia de la fiesta misma-.

${ }^{14}$ Conscientes del impacto publicitario de los balcones, las inmobiliarias colocan carteles con dos superficies formando un ángulo, de modo que parecen salir al encuentro de quienes van por la calle. La presencia en ellos de la palabra Disponible es fiel reflejo de la situación de crisis económica que lleva a algunos propietarios a dejar a elección del interesado en el inmueble si desea comprarlo o alquilarlo.

15 Como afirma Teulón (2004: 40-41), «En todas las ciudades de la Edad Media los comerciantes de todas las actividades de cualquier tipo y de cualquier género, utilizan esta simbología a lo largo de sus tiendas, o en lo alto de sus puertas, para poder informar de qué es lo que pueden encontrar ahí y qué es lo que les puede ofrecer. Esta publicidad exterior en el mismo punto donde se realiza el servicio es lo que a través de la Edad Media se va perpetuando en todos los países conocidos porque no hay otra forma de publicitar». 
icono de la agenda, la impresora, etc.). Es en estos casos donde una imagen puede valer más que mil palabras.

Los balcones informativos no siempre se limitan a señalizar y, en ocasiones, se convierten en auténticos tablones de anuncios e incluso en balcones agenda, como los de algunos pubs, cines y teatros que los utilizan para anunciar sus espectáculos (Hoy fiesta en El Submarino). A ellos se refiere Laura Docampo (2011) en un artículo titulado «La agenda en el balcón»:

La iniciativa del grupo Ochogracia de utilizar como canal de difusión de la agenda cultural del barrio sus propios balcones ha servido para reactivar la participación de los ciudadanos [...]. Con cerca de dos metros de ancho y otros tantos de alto, aquellos carteles comenzaron a despertar la curiosidad de los vecinos [...]. Con esta simple idea han conseguido que los eventos que anuncian se expandan por el barrio como un reguero de pólvora.

Otro tipo de balcones mensajeros son los balcones conativos, que pretenden influir en el receptor y provocar en él una reacción específica ${ }^{16}$, actuando como altavoces de diferentes tipos de mensajes publicitarios y campañas, como esta táctica de guerrilla (Dorrian y Lucas, 2008) que se desarrolló coincidiendo con las fiestas de San Fermín en 2007 y que comenta Manuel Alonso Coto (2008):

Pamplona se llenó de televisiones suicidas, asomadas a balcones con carteles (Que me tiro, que me tiro) o estrelladas contra las aceras. Pocos días después del teaser (abreboca, en la jerga) se descubría que la broma era un anuncio de Directa TV, una nueva cadena que emite solo por Internet. 'Queríamos algo que llegase al público joven y dijese "la tele tradicional tiene miedo", explica Rafael Rodríguez Galobart, de Gap's Comunicación. ¿Funcionó? 'Puede que a algunos les pareciese una chorrada, pero durante aquellos días la gente hablaba de la campaña en la calle; llegar así es precioso

(http://marketing.blogs.ie.edu/archives/2008/06/marketing_de_gu.php).

El BBVA también recurrió a los balcones, a comienzos del año 2011, para promocionar sus planes de pensiones:

Bajo el concepto 'Sí hay futuro', las principales calles de cinco ciudades vistieron de azul sus balcones con pancartas de felicitaciones navideñas con ti-

16 Una modalidad especial de balcones conativos son los que muestran mensajes disuasorios, como los que, a través de elementos no verbales -como alarmas o rejas- e incluso mensajes explícitos, tratan de alejar a los ladrones. 
tulares como 'Feliz 2030' o 'Feliz Año de tu jubilación'. Con esta campaña BBVA quiere animar a sus clientes a realizar aportaciones o traspasos para que puedan conseguir una máxima rentabilidad y seguridad en el futuro (http://www.marketingnews.es/grandescorporaciones/noticia/1055586028205 /bbva-asoma-balcones-promocionar-planes-pensiones.1.html).

Los partidos políticos, especialmente en periodos de campaña, como hemos visto anteriormente, cuelgan sus eslóganes de los balcones de sus sedes. Algunos, en determinados momentos y ante la escasez de espacio, recurren a los balcones de sus simpatizantes -que, de este modo, además, muestran al exterior cuál es su intención de voto-. Así ocurrió en Estepona (Málaga), ante las elecciones municipales y autonómicas de mayo de 2011, a las que concurrían 13 partidos diferentes, según reflejaba Encarna Jerez en un artículo de Málaga hoy:

Apenas queda sitio para hacerse ver, por lo que en un primer momento muchos optaron por empapelar con su cara fachadas, transformadores eléctricos e incluso los monumentos de las rotondas. Todo ha valido por unos días hasta que la Junta Electoral se ha pronunciado [...]. Pero sobre lo que no puede decir nada la Junta Electoral es sobre los espacios privados, por lo que todos los partidos se han apresurado a encargar banderolas para engalanar los balcones de sus seguidores.

Cumplen la función conativa también los mensajes reivindicativos y de protesta, que, a partir de sus afirmaciones rotundas, no dejan a nadie impasible y suelen provocar reacciones. Tanto es así, que da la impresión de que hay balcones que dialogan a través de carteles y señales, mostrando unas veces acuerdo, como si se tratara de gritos al unísono, y otras, desacuerdo, con sus voces disonantes que generan una especie de guerra de balcones, en la que unos dicen y otros contestan en relación con un determinado asunto. En este sentido, podría hablarse de balcones cooperativos - que reflejan un vínculo masivo y un sentimiento ampliamente compartido- y de balcones competitivos - que son los que exhiben, por ejemplo, mensajes en apoyo a uno u otro equipo ante una importante celebración deportiva o a favor o en contra de un determinado proyecto que afecta a toda una comunidad-. Y es que, como afirma José Manuel Martín Corvillo (2011: 18), cuando el grito está escrito delante de nuestros ojos nadie puede hacerse el sordo durante demasiado tiempo. En este sentido, añade Martín Corvillo (2011: 73):

Si cada cartel fuera una boca emitiendo un sonido, estaríamos hablando de un murmullo multitudinario en el que llamar la atención solo sería posible 
forzando un contraste de volumen al alza. Es decir, gritando más que nadie. Inmersos en un mar de mensajes escritos, llamar la atención parece pasar obligatoriamente por hacer un buen uso de cierta recursividad.

Estos balcones conativos pueden cumplir, al mismo tiempo, la función expresiva - por los sentimientos que reflejan-e informativa - por lo que dicen del ocupante-. Algunos gritan su repulsa buscando el apoyo de otros, como los que en 2003 mostraron su rechazo a la intervención en Irak, con su rotundo No a la guerra o con los lemas Queremos la paz, Otro mundo es posible, + amor - guerra y No en nuestro nombre ${ }^{17}$. En esta época, destacaron los balcones protesta según se desprende de las siguientes palabras de Pradel, Duarte, Carbó y Herreros (2005: 43-44) referidas al período comprendido entre febrero y junio de 2003:

Durante estos meses se extendieron distintas formas de protesta, como manifestaciones, concentraciones en plazas y delante de las sedes del PP, recitales, charlas, performances, etc. También se distribuyeron chapas con el icono del movimiento, banderas pacifistas, y se colgaron pancartas de fabricación casera en los balcones.

Los balcones son también un espacio empleado por los ciudadanos para mostrar sus reivindicaciones en el ámbito local. Es el caso, por ejemplo, de los vecinos de Barcelona que exigían que el trazado del tren de alta velocidad no pasara por debajo de sus casas (El AVE por el litoral); los que mostraban su rechazo a la contaminación acústica, la prostitución y la droga, en El Raval, también en Barcelona (Volem un barri digne); los integrantes de la plataforma 0,7 de Badajoz, reclamando al Ayuntamiento que destinara este porcentaje a la cooperación al desarrollo $(0,7 \mathrm{YA})$; los que reivindicaban un Tajo más limpio y con mayor caudal (El Tajo se ahoga); y, los de la plataforma Democracia Real Ya (DRY), con diferentes mensajes (como Sus beneficios. Nuestras crisis. Otro mundo es posible).

No siempre las protestas se expresan a través de mensajes verbales. Así, según reflejaba en un artículo González (2006), la Fundación Galega contra O Narcotráfico hizo un llamamiento para que se colocaran en las fachadas sábanas y paños blancos «en repulsa a las drogas y al narcotráfico», en la comarca de O Salnés y en toda Galicia, y la Asociación de Amas de Casa envió una circular a sus asociadas pidiéndoles sumarse a esta medida «para que

17 En Barcelona, dos balcones exhibieron sendos mensajes complementarios. El de la izquierda decía Aquí hacemos el amor y el de la derecha, No la guerra. 
cada día sigan colgando más sábanas en los balcones hasta que la comunidad sea un manto blanco» ${ }^{18}$.

A veces, el lanzamiento de un mensaje provoca respuestas divergentes, dando lugar, como hemos dicho, a un diálogo o guerra de balcones, según la intensidad de la discordia. Y así, por ejemplo, en el barrio valenciano de El Cabanyal, vecinos contrarios al plan municipal colgaron de sus balcones una pancarta reivindicativa, para mostrar públicamente su rechazo, con el texto Cabanyal, t'estime sencer $i$ viu, mientras que los partidarios del plan y de su aspecto más polémico (la prolongación de una avenida) exhibieron este otro: Els veïns del Cabanyal sí volem la prolongació de Blasco Ibáñez.

En otro contexto bien diferente, cuando en 2010 se celebró el Mundial de Fútbol, muchos ciudadanos españoles colgaron de sus balcones la bandera nacional, en apoyo a la selección. Hubo otros que también quisieron apoyar al equipo español, sólo que luciendo la bandera republicana ${ }^{19}$.

Un tipo especial de balcones conativos son los que defienden la Navidad cristiana, que establecen un diálogo con quienes adoptan la tradición nórdica, representada por Papá Noel. Así, han surgido campañas para adornar los balcones con tapices con el mensaje Dios ha nacido y otros con la imagen de la adoración de los Reyes Magos, como la de HazteOir.org, que, bajo el rótulo Proyecto Feliz Navidad, tiene como objetivo proclamar que la Navidad «no son simplemente vacaciones y regalos», sino anunciar desde cada casa «la buena noticia del nacimiento del Salvador».

Las visitas del Papa a nuestro país han invitado también al diálogo de balcones entre quienes las apoyan y quienes las rechazan. Por un lado, los partidarios cuelgan sus pancartas a lo largo de los recorridos previstos para garantizar un buen recibimiento y, por otro, los opositores, hacen lo mismo mostrando su repulsa. Los organizadores de la Jornada Mundial de la Juventud (JMJ), en agosto de 2011, se ocuparon de engalanar Madrid para re-

18 También nos parece interesante la siguiente reivindicación lanzada a través de los balcones mediante un mensaje no verbal, consistente en la exhibición de un delantal: «A los numerosos actos reivindicativos que se celebrarán hoy jueves 29 de marzo con motivo de la huelga general habrá que sumar una más: colgar un delantal en el balcón de casa. Ése es el curioso y llamativo gesto simbólico que la Asamblea de Mujeres de Bizkaia y la Plataforma para la Marcha Mundial de las Mujeres han promovido para reivindicar que 'el trabajo doméstico y de cuidados no reconocido y carente de derechos y garantías, también es un trabajo’» (www.vidasolidaria.com/noticias/2012-03-28).

${ }^{19}$ El diálogo de ambas banderas en los balcones se ha activado también en diversas ocasiones en que algún miembro de la Familia Real ha visitado alguna población, mostrando los ciudadanos, de este modo, su apoyo-o su rechazo a la institución a la que representan. 
cibir a Benedicto XVI, llevando sus mensajes a los balcones particulares y algunos institucionales - lo que levantó las críticas de los defensores de un Estado laico - y a los puentes - un tipo de balcón muy particular-. Algunos de sus lemas fueron Todos estamos llamados a la santidad, Abrid vuestro corazón a Dios, Dejaos sorprender por Cristo y María, háblanos de Jesús. Quienes se oponían al despliegue ocasionado por la visita mostraron otros mensajes, como De mis impuestos al Papa cero, Menos crucifijos y más trabajo fijo y Menos curas y más cultura ${ }^{20}$.

Entre unos y otros, hay autoridades que tratan de ofrecer una vía de acuerdo apelando a la necesidad de mostrarse como un buen anfitrión. Así lo hizo el entonces alcalde de Barcelona, Jordi Hereu, ante la visita de Benedicto XVI, el 28 de octubre de 2010 a esta ciudad, proponiendo, a través de un bando, que los vecinos colgaran de sus balcones la bandera catalana:

Hereu señala que la capital catalana es una ciudad reconocida por la 'calidez con la que sabe tratar a sus huéspedes', por lo que pide que 'más allá de las creencias' de cada uno, los barceloneses sean los 'mejores anfitriones' [...]. En esta línea, Hereu anima a los barceloneses a que engalanen sus casas con la senyera: 'Nuestra bandera, la que a todos los catalanes nos identifica, representa y hermana' (http://www.periodistadigital.com/religion/espana/2010/10/28/religion-iglesia-hereu-barcelona-alcalde-bando-senyeras-vis ita-papa.shtml).

Entre los balcones expresivos - otra modalidad de balcones mensajeros - tienen especial relevancia los que participan, vistiéndose de gala, de las fiestas religiosas y civiles que recorren el calendario, por la intensa carga de sentimientos que transportan. Flavia Paz Velázquez (1986: 129) se refiere al Corpus Christi, una de las fiestas que más invita a adornar los balcones, y a su «peculiar vestimenta» a comienzos del siglo XX en los cerros de Guadix, a base de «colchas blancas de encaje antiguo o de crochet, mantones bordados, tapices» y lo explica así: «Es lo más íntimo y bello de la vivienda lo que sacan las accitanas del arcón para requebrar el paso del Señor». Los balcones se impregnan también del espíritu festivo durante las celebraciones patronales evidenciado que la comunidad vive conjuntamente una fecha especial. Es el caso de la fiesta de Moros y Cristianos, que se celebra en Alcoi (Alicante) en torno a Sant Jordi, el 23 de abril, y llena todos los balcones -incluido el

${ }^{20}$ En la visita papal del 6 de noviembre de 2010 a Santiago de Compostela algunos vecinos colgaron de sus balcones banderas rojas donde se podía apreciar una señal de tráfico de peligro con una mitra blanca dibujada dentro y el mensaje Eu nom te espero. 
del Ayuntamiento - de banderas y emblemas de unos y de otros: las cruces y las medias lunas cambian por completo la fisonomía de la población.

Los balcones se vuelven asimismo expresivos ante acontecimientos que desvelan los sentimientos de los ciudadanos, como cuando los hinchas de un equipo de fútbol exhiben sus escudos y distintivos, en señal de apoyo, ante la celebración de un partido importante. Así lo reflejaba Francesc Peirón (2009) en un artículo:

Los balcones y las ventanas de Barcelona tienen su propia forma de expresión. Su lenguaje. Se hacen ver y explican el estado de ánimo de la ciudad. Estos días predomina 'el blaugrana al vent'. Del mar a la montaña y del Besòs al Llobregat, los signos identificativos con el Barça se prodigan ante la cita de mañana en Roma, donde se juega la final de la Copa de Europa de fútbol que más expectación y expectativas ha levantado en los últimos años.

En el mismo sentido, bajo el lema Volvemos más unidos que nunca los hinchas del Betis lanzaron, en mayo de 2011, su invitación para celebrar su vuelta a primera división tiñendo de verdiblanco la ciudad y engalanando los balcones con banderas y bufandas del equipo. Los balcones se visten con los colores del club, además de para apoyar, para demostrar alegría cuando se celebra la victoria de un equipo en un campeonato nacional o internacional. En estas fiestas del fútbol (Ortiz, 2006; Llopis, 2006 ${ }^{21}$ ), al igual que en las fiestas religiosas y civiles, los balcones, tanto particulares como institucionales, han adquirido un gran protagonismo. Entre estos últimos, el del Palau de la Generalitat de Catalunya, donde acude la plantilla del Barcelona para celebrar sus títulos, constituye un claro ejemplo, ya que, en opinión de Salvador (2006: 203-204):

És un balcó lligat històricament a moments de gran transcendència $i$ un gran faristol legitimat històricament per dirigir-se al poble de Catalunya en moments crucials [...] Però cal remarcar que en l'actualitat, $i$ significativament, les sortides a la balconada són molt escasses i es reserven pràcticament al F.C. Barcelona, que es converteix, així, en el principal protagonista d'un acte que es representa en el millor escenari per a la celebració d'un ritual patriòtic.

${ }^{21}$ Según este investigador (2006: 116): «El fútbol, y las diversas manifestaciones sociales que en torno del mismo se van creando en la sociedad española actual, constituyen un espacio en el que aún se practica la interacción colectiva, la sociabilidad densa y el ritual entusiasta y emotivo, que, además, se han desarrollado de un modo inusitado». 
Hay, además, balcones que muestran agradecimiento, como los de los habitantes de un pueblo portugués que, en abril de 2010, pudieron utilizar el servicio gallego de salud cuando lo necesitaban:

Banderas españolas cuelgan de los balcones de la localidad portuguesa Valença do Minho. Esta localidad acaba de perder el servicio de urgencias nocturno y ahora los vecinos de Valença se ven obligados a cruzar la frontera para ser atendidos en el centro de salud de Tui, una localidad gallega a un kilómetro de distancia. De esta manera, los vecinos de la localidad portuguesa agradecen al alcalde de Tui su colaboración (http://www.hoy.es/videos/videos-de-hoy/ultima-hora/729890831001-banderas-espanolas-ondean-balcones-localidad-portuguesa-valencaminho.html).

Los balcones no solo expresan sentimientos positivos, de apoyo, alegría y gratitud. A veces también exhiben una gran tristeza, vistiéndose de luto. Así ocurrió, por ejemplo, con los que colgaron crespones negros tras el atentado del $11 \mathrm{M}$ en Madrid $^{22}$. A este respecto nos parece interesante mencionar el siguiente comentario de Ortiz y Sánchez-Carretero (2008: 156):

En una época en la que cada vez consumimos más dolor ajeno a través de los medios de comunicación; una época en el que se intenta disminuir al máximo el dolor propio, incluyendo el producido por la muerte de los seres queridos; en una época en la que los rituales de duelo se simplifican y se depositan en manos de "profesionales del duelo». A la vez que todo esto está ocurriendo, es justo ahora, cuando asistimos a otros rituales de duelo colectivos, a otras formas de expresarnos como grupo ante heridas sociales como la producida por los atentados del 11 de marzo en Madrid.

Los ayuntamientos, como representantes de los ciudadanos, se hacen eco del sentir popular también en momentos de dolor por la muerte, exhi-

${ }^{22}$ Aunque en la actualidad la expresión del luto a través de los balcones, salvo casos en los que hay una gran conmoción general, queda relegada casi exclusivamente a los oficiales, en épocas anteriores el dolor por la muerte de un ser querido ha tenido también su reflejo en balcones particulares. Así lo recuerda Violant i Simorra (1949: 494-504): «El luto solía ser largo y riguroso, con manifestaciones exteriores como el cierre de balcones y ventanas y, sobre todo, la asistencia exclusivamente a actos religiosos y no a regocijos públicos». Domínguez Arjona (2009) recuerda otras manifestaciones de dolor a través de los balcones: «el rodapiés [...] era heraldo de que en aquella casa había un difunto, por lo que en señal de duelo se colocaba de forma vertical, como diciendo que sus habitantes no tenían ganas ni de asomarse al balcón». 
biendo crespones negros ${ }^{23}$ y dejando que las banderas ondeen a media asta. Así ocurre, por ejemplo, ante tragedias como el terremoto de Lorca, acaecido el 11 de mayo de 2011, y asesinatos que provocan el rechazo de la comunidad, como los derivados de la violencia machista.

Finalmente, los balcones mensajeros pueden ser estéticos, cuando su fin primordial es el puro embellecimiento. A veces es así por iniciativa de su dueño y otras, previo estímulo de las administraciones que, de este modo, pretenden mejorar la estética de una localidad, revitalizando esta iniciativa ligada a las fiestas populares ${ }^{24}$. Aunque, para mejorar la imagen de un municipio, las administraciones no siempre recurren a iniciativas estimulantes, como los concursos de balcones, sino también represivas ${ }^{25}$.

Un tipo especial de balcones estéticos, que más que embellecer los edificios, embellecen el ambiente que se respira entre ellos, son los que se impregnan de arte, convirtiendo las vías públicas en museos callejeros. Esta clase de balcones se pueden encontrar, por ejemplo, en determinadas fechas en el municipio alicantino de Gata de Gorgos:

Las telas de 'art al vent' ya cuelgan de los balcones de Gata de Gorgos. Esta exposición de arte urbano [...] ha convertido las calles de Bassa, Duquessa d'Almodóvar y la Plaça de l'Església en un museo al aire libre. 118 artistas de 24 países han colgado sus 'lienzos' de tela en los balcones. La muestra se inspira en la vieja tradición de tender en el exterior de las casas colchas durante las fiestas, pero le imprime un nuevo sentido. Ahora es el arte de vanguardia el

${ }^{23}$ Los lazos de colores son la base de un código lingüístico que, en determinados países, como Estados Unidos, se utiliza con mucha frecuencia para mostrar adhesión. En nuestro país también se pueden citar ejemplos, como el del Ayuntamiento de Sestao que pidió a la ciudadanía, a finales de noviembre de 2007, que colocara banderas negras y lazos blancos en los balcones para expresar su rechazo al maltrato (www.elcorreo.com/vizcay/20071122/margen-izquierda/lazos-balcones-contra-maltrato20071122.htm); y el del Ayuntamiento de Zaragoza que, el 1 de diciembre de 2012, lució en su balcón un lazo rojo para conmemorar el Día Mundial contra el Sida (http://WWW.20MINUTOS.ES/NOTICIA/1238196/0/).

${ }^{24}$ Algunos ayuntamientos animan a los vecinos a decorar sus balcones. El de Potes, por ejemplo, como relata Álvarez (2011) en un artículo, ya ha convocado varias ediciones del concurso Balcones Floridos, considerando que detrás de cada balcón ornamentado: «hay una contribución a la mejora estética de una calle o un edificio; a la mejora de la calidad ambiental; y, sobre todo, a la mejora de la relación vecino entorno urbano, mediante una personal aportación artística al único espacio que es privado, pero que pueden disfrutar todos».

${ }_{25}$ Algunas normas para homogeneizar la imagen de los balcones provocan reacciones en contra, como quedó reflejado en esta noticia: «Protesta en topless contra la medida del Gobierno para embellecer los balcones en Ucrania. Grupos de mujeres protestan en Kiev por la medida del Gobierno que prohíbe tender la ropa y almacenar objetos en los balcones» (La Vanguardia.com, 1 de febrero de 2011. http://www.lavanguardia.com/20110201/54110058763/protesta-en-topless-contra-la-medida-del-gobierno-para-embellecer-los-balcones-en-ucrania.html). 
que ondea en los balcones y transforma las calles del centro urbano (www.diarioinformación.com/benidorm/2011/08/17/arte-colgado-balcones-gata).

De manera similar, las fachadas del Barrio de Ruzafa (Valencia) se convirtieron en una improvisada galería de arte contemporáneo durante las Fallas de 2012 y expusieron en sus balcones un centenar de lienzos realizados por creadores de distintas nacionalidades (http://ccaa.elpais.com/ccaa 12012/02/14valencia/1329243321_771708.html).

En el ámbito literario sobresalen, entre otros, los balcones poéticos que en Córdoba se hacen eco de Cosmopoética, un certamen anual de poesía, al que se refiere Albert (2010) en un artículo de El País:

Se trata del proyecto organizado por el servicio de Capitalidad Cultural del Ayuntamiento, Balcones de poesía, que busca decorar los balcones de las casas tradicionales con lonas que recojan versos de Miguel Hernández [...]. ¿ $V i v e s$ en el casco histórico de nuestra ciudad? ¿Tienes un balcón y te gusta la poesía?'. Desde ayer circula por Internet un correo electrónico destinado a los cordobeses y encabezado con estas preguntas, que buscan voluntarios que quieran convertir sus viviendas en soporte literario.

De esta manera los versos abandonan las páginas de los libros y se instalan en los balcones formando parte del entramado urbano e invitando a los viandantes a relacionarse con la poesía. Así, se humanizan los municipios, se enriquece la ciudad, mejora el entorno cordobés.

\section{CONCLUSIONES}

Tras esta primera aproximación a los balcones, podemos concluir que estos particulares espacios suspendidos en el aire se han convertido en la actualidad en un poderoso soporte comunicativo, como medio de difusión masivo, permanente y económico. Y es que estos elementos arquitectónicos, aparte de actuar como un espejo de doble superficie -puesto que reflejan mucho tanto de sus propietarios como de la sociedad de la que forman parte-, actúan, a menudo, como pantallas desde las que se lanzan mensajes implícitos y explícitos, verbales y no verbales, permanentes y efímeros, estáticos y dinámicos, que exhiben informaciones de todo tipo: de carácter religioso, deportivo, festivo, cívico, comercial o publicitario.

$\mathrm{Al}$ analizar los balcones, hemos visto cómo, desde el punto de vista formal, los mensajes que transportan, al ir dirigidos a un público apresurado, so- 
breestimulado y alejado del soporte, deben ser breves, claros y concisos, tener muy en cuenta su ubicación y recurrir a numerosas estrategias del lenguaje visual, para conseguir la notoriedad que persiguen y atrapar la mirada de conductores y viandantes. Y hemos visto también cómo, desde la perspectiva funcional, los balcones, tanto los oficiales como los institucionales o los particulares, se distinguen por su polivalencia. Todos ellos pueden ser, entre otras cosas, pregoneros, señalizadores, transmisores de alegría y de tristeza, canales de protesta y de propaganda y hasta embellecedores del paisaje urbano en determinadas fechas.

Éste es el presente de los balcones en la sociedad actual, que tienen una importante función como mensajeros, si bien este altavoz, en el futuro, puede ir enmudeciendo ante las restricciones de las normativas municipales, ante la construcción de edificios que prescinden de ellos y ante la preferencia de las generaciones más jóvenes de otros balcones, los virtuales -que les llevan a dirigir sus ojos hacia las pantallas en lugar de hacia las alturas-, para expresarse, para manifestarse y para darse a conocer.

\section{REFERENCIAS BIBLIOGRÁFICAS}

ACASO, M. (2009). El lenguaje visual. Barcelona: Paidós Ibérica.

AGÜERO, R. (2009). El balcón y la celosía, elementos de confort lumínico y térmico en el clima de la ciudad de Lima. Trabajo de Máster. Barcelona. http://masteruniversitaris.upc.edu/aem/informacion-academica/20022-tesinas-finales-de-master/archivos/2008-09/tesinas-completas/rafael-aguero-leon-balcon-y-celosia_comp.pdf (consultado 14-12-2011).

ALBERT, M. J. (2010). «Córdoba busca balcones para Miguel Hernández». elpaís.com. El País. Edición de Andalucía. 18 de febrero. http://elpais.com/diario/2010/02/18/andalucia/1266448932_850215.html (consultado 8-1-2012).

ÁLVAREZ, P. (2011). «Potes anima a sus vecinos a engalanar sus balcones». eldiariomontanes. 24 de junio. http://www.eldiariomontanes.es /20110624/local/occidental-liebana/potes-vecinos-engalanar201106240818.html (consultado 27-11-2011).

BASSAT, L. (1993). El libro rojo de la publicidad (Ideas que mueven montañas). Barcelona: Debolsillo. 10. a edición en este formato (2010). 
BREVA, E. y BALADO, C. (2009). «La creatividad de la publicidad exterior: teoría y práctica a partir de la visión de los creativos». Área abierta 22, 1-18. http://dialnet.unirioja.es/servlet/articulo?codigo $=3112313$ (consultado 27-11-2011).

BREVA, E. (2010). «El medio exterior, más allá de una decisión intuitiva». Zer 29, 271-288.

CASTAÑEDA, J. 2009. Patologías urbanas. Ecografía de una sociedad desestructurada. Barcelona: Niberta.

COSTA, J. (2003). Diseñar para los ojos. Sopocachi: Grupo Dessign.

DE URBINA, J. A. (1989). El arte de invitar. Su protocolo. Barcelona: Consejo Superior de Relaciones Públicas de España.

CANO, I. ; GARCÍA, M.; CASTILLA, A. y SÁNCHEZ, A. (2010). «Diálogo sobre los muros». Revista Huellas. http://www.revistahuellas.es/rh_2010_2/pdf/o7_dialogos\%20sobre\%20los\%muros\%_df_2.pdf (consultado 14-12-2011).

DOCAMPO, L. (2011). «La agenda en el balcón». laopinion.es. 7 de junio. http://www.laopinion.es/tenerife/2011/06/07/agenda-balcon/349983.html (consultado 27-11-2011).

DOMÍNGUEZ ARJONA, J. (2009). «La Sevilla que no vemos. Balcones de luto». 5 de noviembre. www.galeon.com/juliodominguez/20096/rodapies.html (consultado 27-11-2011).

DORRIAN, M. y LUCAS, G. (2008). Publicidad de guerrilla. Otras formas de comunicar. Barcelona: Editorial Gustavo Gili.

GARCÍA-UCEDA, M. (2008). Las claves de la publicidad. Madrid: ESIC. 6. ${ }^{a}$ edición.

GALÁN, C. (2011). «Homo loquens, homo virtualis». Jóvenes en(red)ados. Revista de Estudios de Juventud 93, 11-26.

GARÍ, J. (1995). La conversación mural: ensayo para una lectura del graffiti. Madrid: Fundesco.

GONZÁLEZ, M. (2006). «La Fundación pide más paños blancos en los balcones contra el narcotráfico». farodevigo.es. 10 de febrero. http://www.farodevigo.es/portada-arousa/2536/fundacion-pide-panosblancos-balcones-narcotrafico/45709.html (consultado 8-1-2012).

GUBERN. R. (1988). Mensajes icónicos en la cultura de masas. Barcelona: Lumen. 
JEREZ, E. (2011). «La campaña se asoma al balcón». malagahoy.es. 16 de mayo. http://www.malagahoy.es/article/malaga2011/976519/la/campana/selasoma/balcon.html (consultado 27-11-2011).

JORNET, Ll. (2008). Aceptación social del mobiliario urbano como servicio público y soporte publicitario. Antecedentes, evolución e integración de las distintas concesiones municipales de 1986 a 2005 en Barcelona. Tesis doctoral. Barcelona: Universitat Ramon Llull.

LAGUNA, D. (2010). «La rotulación del pequeño comercio». 29 de junio. http://www.tecneplas.net/noticias/tabid/55/entryid/15/la-rotulacion-delpequeno-comercio.aspx (consultado 15-1-2012).

LLOPIS GOIG, R. (2006). «El fútbol como ritual festivo. Un análisis referido a la sociedad española». Anduli: Revista Andaluza de Ciencias Sociales $6,115-132$.

LÓPEZ JIMÉNEZ, Á. (1998). «El arte de la calle». Reis 84, 173-194.

MALDONADO, R. (2011). «Balcones de Cartagena, únicos en el mundo». Diario del Huila. 10 de julio. http://www.diariodelhuila.com/noticia/16723 (consultado 25-1-2012).

MARTÍN CORVILLO, J. M. (2011). 15 M. Anatomía lingüística de la indignación. Trabajo de Fin de Master. Valencia: Universitat de València.

MESA, M. 2011. «Salir del balcón». arcadia.com. 21 de enero. http://www.revistaarcadia.com/opinion/columnas/articulo/salir-del-balcon/24192 (consultado 25-1-2012).

MOLINER, M. (1998). Diccionario de uso del español. Madrid: Gredos. Vol. 1.p. 329. 2. ${ }^{\text {a edición. }}$

ORTIZ, C. (2006). «La Diosa Blanca y el Real Madrid. Celebraciones deportivas y espacio urbano». Revista de Dialectología y Tradiciones Populares LXI /2, 198-208.

ORTIZ, C. y SÁNCHEZ-CARRETERO, C. (2008). «Archivos etnográficos, memoria y nuevos patrimonios: el caso del Archivo del Duelo». En $\mathrm{Pa}$ trimonios culturales: Educación e interpretación. Cruzando límites y produciendo alternativas, X. Pereiro, S. Prado y H. Takenaka (coords.), 155-170. San Sebastián: Arkulegi. http://www.ankulegi.org/wp-content/uploads/2012/03/1209Ortiz-Garcia.pdf (consultado 25-1-2012).

PAZ VELÁZQUEZ, F. (1986). Raíces Linarenses. Madrid: Narcea. 
PEIRÓN, F. (200). «La 'Barçamanía' toma las calles de Barcelona, que hablan de la ilusión por la Champions». 26 de mayo. http://www.lavanguardia.com/deportes/noticias/20090526/53709782465/la-barsamaniatoma-las-calles-silvia-barsa-barcelona-champions-urgell-madrid-copa-jo an-gamper-las-ve.html (consultado 27-11-2011).

PÉREZ, E. (2010). «No a la guerra en los balcones». revistarambla.com. 6 de septiembre. http://www.revistarambla.com/vl/index.php/cultura/fotografia/310-no-a-la-guerra-en-los-balcones (consultado 27-11-2011).

PRADEL, M.; DUARTE, M.; CARBÓ, R. y HERREROS, T. (2005), «La última oleada de movilizaciones (2002-2004)». En La política en la red. Anuario de movimientos sociales, E. Grau y P. Ibarra (coords.), 34-52. Barcelona: Ikaria Editorial.

RODRÍGUEZ, I.; SUÁREZ, A. y GARCÍA, M. (2008). Dirección publicitaria. Barcelona: UOC.

ROJO, J.A. (2008). «Entrevista a Boris Groys: 'El consumo es hoy la gran ideología'». El País. Babelia. 26 de julio. http://elpais.com/diario/2008/07/25/babelia/1217029811_850215.html (consultado 27-112011).

SALVADOR, J. J. (2006). Fútbol, metáfora d'una guerra freda, un estudi antropològic del Barça. Tesis Doctoral. Tarragona: Universitat Rovira Virgili.

TEULÓN, L. (2004). «Los soportes de la publicidad exterior». En La publicidad local, R. López, Fr. Fernández y Á. Durán (eds.), 39-52. Castelló de la Plana: Publicacions de la Universitat de Castelló.

VV. AA. (2008). Diccionario visual de términos arquitectónicos. Madrid: Ediciones Cátedra (Grupo Anaya, S.A.). 2. edición (2009).

VERDÚ, V. (2003). El estilo del mundo. La vida en el capitalismo de ficción. Barcelona: Anagrama.

VIOLANT I SIMORRA, R. (1949). El Pirineo español. Madrid.

Recibido el 23 de mayo de 2012.

Aceptado el 30 de septiembre de 2012. 
